\title{
Abattoir-Based Serological Surveillance for Transboundary and Zoonotic Diseases in Cattle and Swine in Cambodia: A Pilot Study in Phnom Phen Province During 2019 and 2020.
}

\section{Jarunee Siengsanan-Lamont}

Mahidol Oxford Tropical Medicine Research Unit https://orcid.org/0000-0002-6125-4544

\section{Sothyra Tum}

National Animal Health and Production research institute

\section{Lida Kong}

Mahidol Oxford Tropical Medicine Research Unit

Paul W. Selleck

Mahidol Oxford Tropical Medicine Research Unit

Laurence J. Gleeson

Mahidol Oxford Tropical Medicine Research Unit

Stuart D. Blacksell ( $\nabla$ stuart@tropmedres.ac)

Mahidol Oxford Tropical Medicine Research Unit

\section{Research Article}

Keywords: Zoonoses, Animal disease surveillance, Cambodia, ASF, CSF, PRRS, brucellosis, Q fever

Posted Date: August 13th, 2021

DOI: https://doi.org/10.21203/rs.3.rs-694599/v1

License: (c) (i) This work is licensed under a Creative Commons Attribution 4.0 International License.

Read Full License 


\section{Abstract}

A pilot animal disease surveillance program was implemented at four abattoirs in Phnom Penh, Cambodia between October 2019 to January 2020. A total of 1,141 samples were collected from 477 cattle and 664 swine. Serological testing was performed using commercial antibody ELISA kits for zoonotic and high impact animal diseases, namely brucellosis, Q fever, CSF, PRRS and ASF. Only two samples tested positive for brucella antibodies $(0.2 \%(0.4,0.6), n=1,141)$. The seroprevalences of $Q$ fever was $0.8 \%(0.3,2.1, n=477)$ in the cattle samples while CSF, PRRS and ASF in pigs were $55.4 \%(51.6,59.2$, $n=655), 81.2 \%(78.1,84.0, n=655)$ and $2.6 \%(1.6,4.1, n=664)$, respectively. All 38 doubtful and 17 positive ASF antibody ELISA samples were negative when tested by real-time PCR. Statistical analyses demonstrated that the factors that were significantly associated with positive results of $Q$ fever was sampling date ( $p$-value $=0.04)$, and for ASF was the location of the abattoir ( $p$-value $=0.002)$. Significant risk factors for both CSF and PRRS were the province of origin of the animals (CSF: $p$-value $=0.002$; PRRS: $p$-value $=0.004)$ and sample collection month (CSF: $p$-value $=1.6 \times 10^{-6} ;$ PRRS: $p$-value $=4.8 \times$ $10^{-13}$ ). In conclusion, the prevalence of zoonotic diseases tested for in this study were very low. The high prevalences of CSF and PRRS antibodies were most likely the result of vaccination. All ASF seropositive pigs, including those that gave equivocal results, originated from large-scale Cambodian-based commercial farms, as well as Thailand, which raises questions about possible illegal vaccination or lowpathogenicity ASF variants. The pilot abattoir serosurveillance program described here has the potential to provide a sentinel for incursions of novel and endemic pathogens although further work is required to demonstrate its capacity to provide information on the longitudinal disease trends.

\section{Introduction}

The Kingdom of Cambodia is a country with approximately 16 million people where livestock production provides livelihood, nutritional and food security for its people (Holl, 2018). Meat consumption and animal production in Cambodia is increasing due to population and economic growth, and urbanization (Darith et al., 2017). Smallholder livestock raisers face threats from multiple endemic diseases including foot and mouth disease (FMD), Haemorrhagic Septicaemia, Classical Swine Fever (CSF) (Shankar et al., 2012), Porcine Reproductive and Respiratory Syndrome (PRRS) (Goutard et al., 2015) and more recently African swine fever (ASF). For the past two decades, animal disease surveillance activities in Cambodia have focussed on emerging infectious diseases (EIDs) including highly pathogenic avian influenza (Desvaux et al., 2006; Ear, 2012; Horm et al., 2013) with few publications on surveillance of other high impact transboundary animal diseases including FMD (Tum et al., 2015; Vergne et al., 2011). There is also limited surveillance information on brucellosis (Sothoeun, Young \& Windsor, 2013) and Q fever, two potentially important zoonoses.

Cambodia has limited human resources and diagnostic capacity and capability and has relied on international agencies to support animal disease surveillance activities (Desvaux et al., 2006; Goutard et al., 2015). A present, there is no routine surveillance program to compile animal disease information, although there was national interest to trial a readily applicable surveillance program to fill this gap. The 
surveillance program described in this study was initiated by the Cambodian government and the testing was done with the guidance of Mahidol-Oxford Tropical Medicine Research Unit (MORU) staff at the National Animal Health and Production Research Institute (NAHPRI) located in Phnom Penh. The objectives of the program were to determine seroprevalences of endemic high impact diseases, to strengthen national capability in disease surveillance and detection and to develop a sustainable animal disease surveillance system. The outcomes from this study were expected to contribute to the knowledge of disease prevalence in Cambodian livestock and further improvement of disease control measures and livestock production in the country.

\section{Material And Methods}

\section{Site selection and Sample size calculation}

For this trial, four abattoirs in Phnom Penh Municipality namely Boeng Salang (processing swine and cattle), Chrouy Changya (processing cattle only), Damnak Thum (processing swine only), and Trea Boun (processing swine only) slaughterhouses were selected based on high numbers of livestock processed per day and convenient access. The Boeng Salang and Chrouy Changya slaughterhouses are relatively large, processing around 300-400 and 120-150 cattle per day respectively, while the other two facilities process less animals per day (Asia Beef Network, 2020). Samples were collected between October 2019 to January 2020. The sample size calculation was based on Cannon and Roe's technique using an expected prevalence of approximately $10 \%$, test sensitivity of $90 \%$ and estimated population size $(\mathrm{N})$ of 50 animals (Cannon \& Roe, 1982). Thus, the sample collection team (comprised of two NAHPRI staff, an abattoir veterinarian from the provincial office and a veterinarian from MORU) was directed to randomly collect at least $30 \%$ of the total number of animals slaughtered on the collection day. Each abattoir was visited three times during the study except Boeng Salang slaughterhouse which was visited six times in total (three each for cattle and for swine samples). Information including the number and type of animals slaughtered at the abattoir on the sampling day, and where known the biodata of the sampled animals (e.g., country, province or farm of origin, trader/owner and vaccination status), were recorded.

\section{Sample preparation and storage}

Blood samples were collected from the jugular vein of swine and cattle then transferred to labelled vacutainers without anticoagulant. The vacutainers were placed in a rack sealed in a large zip-lock plastic bag and kept in a cooler with freezer packs while being transported back to NAHPRI. Once the blood samples arrived at NAHPRI, serum was separated within 24 hours using a refrigerated centrifuge. The serum (supernatant) was pipetted into a labelled microcentrifuge tube (or cryotube). The serum samples were stored at $2-8^{\circ} \mathrm{C}$ while handling and kept at $-20^{\circ} \mathrm{C}$ or lower in an allocated freezer for long term storage.

\section{Laboratory diagnostic tests}


Commercial enzyme-linked immunosorbent assay (ELISA) kits manufactured by ID.VET[1], France were used to detect antibodies against Coxiella burnetii (ID Screen ${ }^{\circledR} \mathrm{Q}$ fever indirect multi-species, Cat\# FQSMS-5P), Brucella abortus, melitensis or suis (ID Screen ${ }^{\circledR}$ brucellosis serum indirect multi-species, Cat\# BRUS-MS-10P), porcine reproductive and respiratory syndrome (PRRS) virus (ID Screen ${ }^{\circledR}$ PRRS indirect, Cat\# PRRSS-5P), classical swine fever (CSF) virus E2 glycoprotein (ID Screen ${ }^{\circledR}$ classical swine fever E2 competition, Cat\# CSFE2C-5P) and African swine fever (ASF) virus (ID Screen ${ }^{\circledR}$ African swine fever competition, Cat\# ASFC-5P). ELISAs were done according to the manufacturer's protocols provided with the kits. The Sample to positive ratio (S/P\%) and competition percentage (S/N\%) were calculated using IDSoft ${ }^{\mathrm{TM}}$ software provided with the ID Screen ${ }^{\circledR}$ ELISA kits (ID.VET, 2014). The S/P\% cut off points and diagnostic sensitivities (Dse) and specificities (Dsp) for the brucellosis and Q fever kits were previously described (Siengsanan-Lamont et al., 2021). The PRRS ELISA kit's S/P\% cutoff points, Dse and Dsp were respectively $S / P \leq 0.4=$ negative and $S / P>0.4=$ positive, $D s e=100 \%$ and $D s p=99.9 \%$ (ID.VET, 2020). The S/N\% cutpoints, Dse and Dsp of the CSF kit were S/N\% $\leq 50 \%=$ positive, $50 \%<\mathrm{S} / \mathrm{N} \% \leq 60 \%=$ doubtful, S/N\% $>60 \%=$ negative, Dse $=100 \%$, Dsp $=100 \%$ (ID.VET, 2019) and the ASF kit were S/N\% $\leq$ $40 \%=$ positive, $40 \%<\mathrm{S} / \mathrm{N} \%<50 \%$ = doubtful and $\mathrm{S} / \mathrm{N} \% \geq 50 \%=$ negative, Dse $=95.8 \%$ and $\mathrm{Dsp}=99.4 \%$ (CISA-INIA, 2015). Samples testing positive and doubtful positive for brucellosis antibodies ELISA were confirmed by the rose bengal test (RBT) (OIE, 2018). Samples that tested positive and doubtful positive in the ASF antibody ELISA were then tested by real-time PCR using primers and protocol described by the World Organization for Animal Health (OIE, 2019) .

\section{Statistical analysis}

Descriptive statistical, apparent seroprevalence, true prevalence (using Dse and Dsp published in previous papers), risk factor and spatial analyses were performed in Microsoft Excel (Microsoft Corporation, 2020) and R Studio Version 1.2.1335 (RStudio Team, 2015). Frequency and probability distributions were used to explain the dataset. Apparent and true seroprevalences were estimated applying the Wilson method suggested for imperfect tests (Reiczigel, Földi, \& Ózsvári, 2010) using the epiR package (Stevenson, 2020). Given the disease prevalences were low, Fisher's exact test was used to determine the associations between a factor for seropositive and seronegative animals (Soetewey, 2020). The variables sampling date, sampling month, sex, age, animal origin, origin province (or country) and abattoir were tested against the ELISA results. As individual abattoirs in Phnom Penh sourced animals from different locations, the abattoir was considered as one of the variables. Where applicable, univariate (Chi-square) and multivariate logistic regressions were fitted to identify potential risk factors. A subset of variables with a p-value $<0.1$ in the univariate model were included in multivariate analyses (Souriya et al., 2019). The final model was selected based on 1) all variables in the model had $p$-value $<0.05$ tested by analyses of variance (ANOVA), Chi-square test (Fox, 2020) and 2) the model had the lowest Akaike Information Criterion (AIC). The goodness of fit of the final model was tested using Hosmer-Lemeshow $\chi 2$ test (DeCook, 2011). Visualization of animal movement data was generated using the leaflet $\mathrm{R}$ package (Graul, 2016). 


\section{Footnote:}

[1] ID.VET: 310 rue Louis Pasteur, 34790 Grabels, FRANCE, https://www.id-vet.com/

\section{Results}

This trial was implemented between October 2019 to January 2020, and was curtailed to some extent by the occurrence of COVID-19 in the country. A total of 1,141 (477 cattle and 664 pigs) samples were collected during this period. The overall seroprevalence of diseases are given in Table 1, including appearance and true prevalence taking into account diagnostic sensitivities and diagnostic sensitivities. The numbers of animal samples collected per calendar month is presented in Table 2. The survey design suggested to sample $~ 30 \%$ of animals present at the abattoir on the sample collection days, so the numbers of samples collected on each visit varied depending on this factor. The average cost of field sample collection including staff per diem, transportation and field equipment and consumables was approximately USD 2 per sample, while the cost of the field consumables alone was approximately USD 0.5 per sample. The cost of a serological diagnostic test and laboratory consumables ranged between USD 0.8 and USD 3.8 per sample depending on the pathogen.

Table 1

Overall serological test results

\begin{tabular}{|c|c|c|c|c|}
\hline Type & Disease & Positive & $\begin{array}{l}\text { \%Apparent seroprevalence } \\
(95 \% \mathrm{Cl})\end{array}$ & \%True seroprevalence (95\% Cl) \\
\hline \multirow{2}{*}{$\begin{array}{l}\text { Cattle } \\
(n= \\
477)\end{array}$} & Brucellosis & 1 & $0.2(0.0,1.2)$ & - \\
\hline & Q Fever & 4 & $0.8(0.3,2.1)$ & $0.8(0.3,2.1)$ \\
\hline \multirow{4}{*}{$\begin{array}{l}\text { Swine } \\
(n= \\
655)\end{array}$} & Brucellosis & 1 & $0.2(0.0,0.9)$ & - \\
\hline & CSF & 363 & $55.4(51.6,59.2)$ & $55.4(51.6,59.2)$ \\
\hline & PRRS & 532 & $81.2(78.1,84.0)$ & $81.2(78.1,84.0)$ \\
\hline & $\begin{array}{l}\text { ASF }(n= \\
\left.664^{*}\right)\end{array}$ & 17 & $2.6(1.6,4.1)$ & $2.1(1.1,3.6)$ \\
\hline
\end{tabular}


Table 2

Monthly sample counts and apparent seroprevalence percentage of each disease

\begin{tabular}{|c|c|c|c|c|c|c|c|}
\hline \multirow[t]{2}{*}{ Species } & \multirow{2}{*}{$\begin{array}{l}\text { Collection } \\
\text { Month }\end{array}$} & \multirow{2}{*}{$\begin{array}{l}\text { Total } \\
\text { (n) }\end{array}$} & \multicolumn{5}{|c|}{ \%Seroprevalence $(95 \% \mathrm{Cl})$} \\
\hline & & & Brucellosis & Q fever & PRRS & CSF & ASF \\
\hline \multirow[t]{3}{*}{ Cattle } & Nov 2019 & 10 & $\begin{array}{l}0.0\left(2 \times 10^{-}\right. \\
15,27.8)\end{array}$ & $\begin{array}{l}10.0 \\
(0.5 \\
40.4)\end{array}$ & $\mathrm{n} / \mathrm{a}$ & $\mathrm{n} / \mathrm{a}$ & $\mathrm{n} / \mathrm{a}$ \\
\hline & Dec 2019 & 181 & $0.0(0,2.1)$ & $\begin{array}{l}0.6(0.0 \\
3.1)\end{array}$ & $\mathrm{n} / \mathrm{a}$ & $\mathrm{n} / \mathrm{a}$ & $\mathrm{n} / \mathrm{a}$ \\
\hline & Jan 2020 & 286 & $\begin{array}{l}0.3(0.0 \\
2.0)\end{array}$ & $\begin{array}{l}0.7(0.2, \\
2.5)\end{array}$ & $\mathrm{n} / \mathrm{a}$ & $\mathrm{n} / \mathrm{a}$ & $\mathrm{n} / \mathrm{a}$ \\
\hline \multirow[t]{4}{*}{ Swine } & Oct 2019 & 58 & $0.0(0,6.2)$ & $\mathrm{n} / \mathrm{a}$ & $\begin{array}{l}72.4(59.8, \\
82.2)\end{array}$ & $\begin{array}{l}46.6(34.3, \\
59.2)\end{array}$ & $\begin{array}{l}3.4(1.0 \\
11.7)\end{array}$ \\
\hline & Nov 2019 & 10 & $\begin{array}{l}0.0\left(2 \times 10^{-}\right. \\
15,27.8)\end{array}$ & $\mathrm{n} / \mathrm{a}$ & $\begin{array}{l}0.0\left(2 \times 10^{-}\right. \\
15,27.8)\end{array}$ & $\begin{array}{l}0.0\left(2 \times 10^{-}\right. \\
15,27.8)\end{array}$ & $\begin{array}{l}0.0\left(2 \times 10^{-15}\right. \\
27.8)\end{array}$ \\
\hline & Dec 2019 & 178 & $\begin{array}{l}0.6(0.0 \\
3.1)\end{array}$ & $\mathrm{n} / \mathrm{a}$ & $\begin{array}{l}70.8(63.7, \\
77.0)\end{array}$ & $\begin{array}{l}44.9(37.8, \\
52.3)\end{array}$ & $4.5(2.3,8.6)$ \\
\hline & Jan 2020 & 409 & $0.0(0,0.9)$ & $\mathrm{n} / \mathrm{a}$ & $\begin{array}{l}89.0(85.6, \\
91.7)\end{array}$ & $\begin{array}{l}62.6(57.8, \\
67.1)\end{array}$ & $\begin{array}{l}1.7(0.8,3.4 \\
\left.n=418^{*}\right)\end{array}$ \\
\hline
\end{tabular}

For cattle, $43.2 \%(n=477)$ of the samples collected were from cattle imported from Thailand. For cattle of Cambodian origin, $(n=271), 41.1 \%, 14.3 \% .12 .5 \%$ and $10.7 \%$ were from Takeo, Kampong Cham, Pursat and Kampong Speu provinces, respectively. Only 23.7\% $(n=664)$ of swine samples were pigs imported from Thailand (Table 3). The rest of the swine samples were from local animals from multiple provinces in Cambodia, with 92.9\% $(n=506)$ from commercial pig production farms. The origins of animals were plotted onto a map for visualization of animal movements (Fig. 1). The age of cattle sampled ranged from 1-8 years old, with a majority of $28.5 \%(n=477)$ aged 4 years old. However, the age of the abattoirsampled pigs was not consistently recorded. No vaccination history was recorded as animals were delivered to abattoirs by middlemen who did not have individual animal data. There was one bovine and one pig that tested positive for Brucella antibodies and both originated from Takeo province. All four Q fever seropositive samples $(n=477)$ were collected on the same day from the same abattoir with animals that originated from Takeo province. 
Table 3

Summary of swine sample seroprevalence results

\begin{tabular}{|c|c|c|c|c|c|}
\hline \multirow[t]{2}{*}{ Abattoir } & \multirow{2}{*}{$\begin{array}{l}\text { Origin } \\
\text { province }\end{array}$} & \multirow{2}{*}{$\begin{array}{l}\text { Total } \\
\text { (n) }\end{array}$} & \multicolumn{3}{|c|}{ \%Seroprevalence $(95 \% \mathrm{Cl})$} \\
\hline & & & CSF & PRRS & ASF \\
\hline \multirow[t]{5}{*}{$\begin{array}{l}\text { Boeng } \\
\text { Salang }\end{array}$} & $\begin{array}{l}\text { Kampong } \\
\text { Speu }\end{array}$ & 132 & $\begin{array}{l}37.1(29.4, \\
45.6)\end{array}$ & $\begin{array}{l}78.8(71.1, \\
84.9)\end{array}$ & $0.8(0.0,4.2)$ \\
\hline & Prey Veng & 9 & $\begin{array}{l}44.4(18.9, \\
73.3)\end{array}$ & $\begin{array}{l}\text { 66.7 (35.4, } \\
87.9)\end{array}$ & $0.0(0,29.9)$ \\
\hline & Svay Reing & 5 & $\begin{array}{l}80.0(37.6, \\
99.0)\end{array}$ & $\begin{array}{l}80.0(37.6, \\
99.0)\end{array}$ & $0.0\left(3.1 \times 10^{-15}, 43.4\right)$ \\
\hline & Takeo & 20 & $\begin{array}{l}10.0(2.8 \\
30.1)\end{array}$ & $\begin{array}{l}55.0(34.2, \\
74.2)\end{array}$ & $0.0\left(1.2 \times 10^{-15}, 16.1\right)$ \\
\hline & Thailand & 9 & $\begin{array}{l}44.4(18.9, \\
73.3)\end{array}$ & $\begin{array}{l}77.8(45.3, \\
93.7)\end{array}$ & $11.1(0.6,43.5)$ \\
\hline \multirow[t]{3}{*}{$\begin{array}{l}\text { Damnak } \\
\text { Thum }\end{array}$} & $\begin{array}{l}\text { Kampong } \\
\text { Speu }\end{array}$ & 125 & $\begin{array}{l}53.6(44.9, \\
62.1)\end{array}$ & $\begin{array}{l}82.4(74.8, \\
88.1)\end{array}$ & $\begin{array}{l}5.2(2.6,10.4 ; n= \\
\left.134^{*}\right)\end{array}$ \\
\hline & Sihanoukville & 31 & $\begin{array}{l}48.4(32.0, \\
65.2)\end{array}$ & $\begin{array}{l}71.0(53.4, \\
83.9)\end{array}$ & $9.7(3.3,24.9)$ \\
\hline & Thailand & 29 & $\begin{array}{l}55.2(37.5, \\
71.6)\end{array}$ & $\begin{array}{l}89.7(73.6, \\
96.4)\end{array}$ & $6.9(1.9,22.0)$ \\
\hline \multirow[t]{4}{*}{ Trea Boun } & $\begin{array}{l}\text { Kampong } \\
\text { Speu }\end{array}$ & 147 & $\begin{array}{l}74.8(67.2 \\
81.2)\end{array}$ & $\begin{array}{l}86.4(79.9, \\
91.0)\end{array}$ & $1.4(0.4,4.8)$ \\
\hline & Takeo & 18 & $\begin{array}{l}27.8(12.5, \\
50.9)\end{array}$ & $\begin{array}{l}55.6(33.7 \\
75.4)\end{array}$ & $5.6(0.3,25.8)$ \\
\hline & Thailand & 120 & $\begin{array}{l}70.8(62.1, \\
78.2)\end{array}$ & $\begin{array}{l}\text { 88.3 (81.4, } \\
92.9)\end{array}$ & $0.0(0.3 .1)$ \\
\hline & Unknown & 10 & $\begin{array}{l}20.0(5.7 \\
51.0)\end{array}$ & $\begin{array}{l}60.0(31.3, \\
83.2)\end{array}$ & $0.0\left(2 \times 10^{-15}, 27.8\right)$ \\
\hline
\end{tabular}

Seroprevalence of the Cambodian large commercial farm-origin pigs was $53.8 \%(n=461)$ for CSF, $81.1 \%$ for PRRS $(n=461)$ and $3.0 \%$ for ASF $(n=470)$. While seroprevalence for the Thai-origin pigs $(n=158)$ for CSF, PRRS and ASF were $66.5 \%, 88.0 \%$ and $1.9 \%$ respectively. Only 36 local swine samples were recorded as not from a large commercial farm. These demonstrated seroprevalence of $27.8 \%$ for CSF, $52.8 \%$ for PRRS and $0 \%$ for ASF. Seropositive ASF samples were collected from pigs originating from Kampong Speu, Takeo, Sihanoukville provinces and Thailand. A total of 55 swine samples (38 equivocal and 17 positives to the ASF antibody ELISA) were negative when tested using real-time PCR to check for the presence of the ASF genomic material in the sample. 
Fisher's Exact method was used to determine the association of each of the recorded variables compared with antibody status for brucellosis, Q fever and ASF as the overall number of seropositive samples was low. The variable that demonstrated significant differences between positive and negative results for $Q$ fever was the sampling date $(p$-value $=0.04)$ while for ASF the factor was the abattoir $(p$-value $=0.002)$. No factor was significantly different between positive and negative brucellosis samples. For CSF and PRRS datasets, univariate (Chi-square) and multivariate logistic regressions were fitted. Significant risk factors for both CSF and PRRS were the samples province of origin (CSF: $p$-value $=0.002$; PRRS: $p$-value $=0.004$ ) and sample collection month (CSF: $p$-value $=1.6 \times 10^{-6}$;PRRS: $p$-value $=4.8 \times 10^{-13}$ ).

\section{Discussion}

Animal health surveillance activities in Cambodia are limited with only a small number of neglected parasitic diseases and FMD surveillance programs supported by the government. Other programs including influenza (Goutard et al., 2015; Osbjer et al., 2017), Japanese Encephalitis, West Nile (Auerswald et al., 2020) and wildlife disease (Hul et al., 2021) surveys have been supported by international organizations and/or aid agencies. To support the animal health service to strengthen disease surveillance activities, our study chose abattoir-based surveillance over structured surveillance as it is simpler to implement in a low-resource setting. Even though disease information collected from an abattoir surveillance program has limitations and may not represent the true prevalence of diseases in the population (Cannon \& Roe, 1982), it is still useful to provide an indication of the likely prevalence and therefore probable impact of diseases, as well as indications of geographic distribution, for further investigation. Important in this context, a study by Blacksell et al. (2008) also demonstrated that overall FMD seropositivity detected by structured and abattoir surveys were relatively similar.

A major constraint identified during our study was that central staff from NAHPRI were well-trained and often facilitated field sample collections with little assistances from abattoir veterinarians, resulting in limited knowledge transfer and capacity building of on-site staff. Another constraint was the lack of laboratory capability and capacity due to inadequate human and financial resources. Capacity building of field provincial officers (i.e. abattoir veterinarians, animal health workers, etc.) in disease surveillance, sample collection, submission, case reporting and biosafety principles are critical for early detection and disease monitoring and control. Currently, many field investigations are performed by NAHPRI staff. The average cost of the field consumables per sample in Cambodia was half of the cost of those previously reported in a similar program in Lao PDR (Siengsanan-Lamont et al., 2021). Local supplies are widely available in Cambodia resulting in the lower cost of consumables. However, in looking at costeffectiveness and sustainability the cost of the diagnostic test kits must also be considered. In this instance, specific project resources supported the surveillance in order to obtain baseline indications of prevalence and to guide how to build a system for the longer term. The question arises as to the longerterm utility of such a surveillance system. The system might be used from time to time to get a snapshot of the likely prevalence of priority diseases, especially zoonoses, in the livestock population. In a similar 
program in Lao PDR, the surveillance activity and associated training has also provided capacity building for field surveillance and laboratory diagnosis and was generally met with positive attitudes of field staff.

The total numbers of samples collected per trip varied depending on the numbers of animals processed for slaughter on the sample collection days. Animals were often delivered to slaughterhouses by traders or delivery drivers who may or may not have had full records of individual animals, but generally did not. Thus, some biodata, especially vaccination history, was not available, but if animals originated from outside the country this was generally known. Interpretation of the results needed to take into account biases caused by these limitations of the sample and data collections. An interesting observation from the study was the significant numbers of animals of Thai origin processed in the Cambodian abattoirs and previous studies have reported similar findings. Cambodia has previously been reported as a thoroughfare for cattle from Myanmar and Thailand to Vietnam and China (Pham et al., 2015). Declining cattle production in Cambodia coupled with an increased demand for animal protein (Olmo et al., 2017) has driven the importation of livestock, with the sample in this study revealing that a large proportion ( $43 \%$ ) of cattle processed in these slaughterhouses in Phnom Penh had come in from Thailand. Pisei (2020) reported that Cambodia imported around 20\% ( 2,000-3,000 live pigs/day) of its pigs from Thailand. Another study in 2012 reported that Cambodia imported pigs and cattle from Thailand and cattle from Vietnam (Kerr, Sieng, \& Scoizec, 2013). However, our study had no record of animals at the abattoir from Vietnam. The absence of animals from Vietnam was likely due to the first ASF outbreak in Vietnam in February 2019 (Woonwong, Do Tien, \& Thanawongnuwech, 2020) at which time the Cambodian government banned the importation of pigs from Vietnam in March 2019 (Xuxin, 2019). There are three large scale commercial piggery companies in Cambodia owned by multinational regional agribusiness companies (Pisei, 2020) which were the sources of most swine samples in our study. In May 2020, the General Directorate of Animal Health and Production at the Ministry of Agriculture, Forestry and Fisheries announced a reduction of live pigs imports from neighbouring countries, mainly from Thailand, to 1,800-2,100 head per day and a prohibition of the transit of live pigs from Thailand to Vietnam, to help support local pig production (Chan, 2020). As demand for red meat continues to grow (Woonwong, Do Tien, \& Thanawongnuwech, 2020; Young et al., 2014), movements of animals and animal products continue to pose a risk for spreading transboundary animal diseases. It is a major challenge for Cambodian authorities to maintain meat supplies and at the same time prevent the movement of serious livestock diseases into the country. Currently, ASF poses a major threat to pig production in Cambodia, especially at the smallholder level in villages. And lumpy skin disease (LSD) is also threatening the cattle population in the region as it has become widespread in China (Roche et al., 2021), and recent outbreaks have been reported in Thailand (Sripiachai, 2021). Abattoir surveillance might be useful to monitor the prevalence of endemic disease conditions, or to quickly establish the distribution and impact of a recently introduced disease (e.g. PRRS). And it may help detect a new disease with less dramatic clinical manifestations, such as LSD.

In this study, the seroprevalence of Q fever and brucellosis in cattle was relatively low. In 2008, 120 cattle samples collected from six villages in three provinces in Cambodia tested negative to brucellosis by RBT (Sothoeun, Young, \& Windsor, 2013). Another study conducted in 2015 in Sa Kaeo province, Thailand 
(located close to the Thai-Cambodian border) reported that the herd-level seroprevalence of brucellosis and Q fever of beef cattle were $2.6 \%(95 \% \mathrm{Cl} 0.9,7.3)$ and $4.3 \%(95 \% \mathrm{Cl} 1.8,9.6)$ (Colombe et al., 2018). Brucellosis and Q fever are zoonoses and pose a public health risk, especially to people who closely contact with infected animals (Mori \& Roest, 2018). Further investigation in Takeo province where seropositive animals originated could provide more information on the disease distribution. It is interesting that both these diseases have a very low seroprevalence in Cambodia, where there are no control programs in place. On the other hand, a study by Colombe et al. (2018) reported the seroprevalence of brucellosis and Q fever in small ruminants at a Thai- Cambodia border community at $13.3 \%$ and $33.3 \%$ respectively. Our surveillance did not collect small ruminant samples as these animals are commonly slaughtered at the household level or restaurants. A surveillance program of both diseases in other susceptible hosts like small ruminants would be required to better understand these zoonotic disease risks in the human population.

Interpretation of the CSF and PRRS serology results is difficult as these abattoir-collected samples had no vaccination history, and vaccination programs for large commercial pig farms in Cambodia were commercial-in-confidence. Vaccines against CSF and PRRS are commonly used in pig production in South East Asia (Kunavongkrit \& Heard, 2000; Thammakarn, Hung, \& Eardmusic, 2018; Zhang et al., 2017) and are widely available in Cambodia. Moreover, the diagnostic kits used in this study could not differentiate antibodies arising post-vaccination from those arising post-infection. High seroprevalences of CSF and PRRS detected in our study most likely resulted from vaccine-induced antibodies as more than $90 \%$ of the pig samples were from large commercial farms. Thai pigs showed higher seroprevalence than the Cambodian large commercial farm pigs. On the other hand, the seroprevalence of CSF and PRRS in pigs from the local small scale commercial farms may indicate some natural infection. CSF and PRRS vaccine use in smallholders and semi-commercial farms were reportedly low (Sothoeun, Young, \& Windsor, 2013; Tornimbene et al., 2014; Tornimbene et al., 2015; Zhang et al., 2017). However, the total samples from local small to medium holders were really low in our study. Information on vaccination records and actual practices in commercial farms and smallholders would help explain the findings. The low numbers of smallholder pigs at abattoirs likely reflected population decline (due to competition from commercial piggeries, and perhaps ASF outbreaks) and cultural practices where these pigs were often slaughtered at the household level.

Risk factor analyses suggested that factors including sampling dates, sampling months, abattoirs location, and animal origin were potential predictors of sero-reactors. However, there is not enough information at this stage to conclude the role these factors play. The animal origin factor was not significantly correlated with the seropositive $Q$ fever samples despite all four positive samples originated from Takeo. In the case of ASF tests, only the abattoir variable was significantly correlated to seropositive samples, not the animal origin. These observations could be due to the animal origin variable having a much larger denominator compared to the collection date for the $\mathrm{Q}$ fever dataset and to the abattoir for the ASF dataset. Further investigation in the areas where positive animals originated from would provide more in-depth disease information. The first confirmed ASF cases were reported in Ratanakiri province in April 2019, then five other provinces close to the Vietnam border were also confirmed with ASF outbreaks 
(FAO, 2020). Control measures implemented by the Cambodian government included movement controls on live pigs, and pig products and stamping out in the affected areas (FAO, 2020). However, scientific publications on ASF control in Cambodia were not available at the time of our study. All ASF antibody positive and doubtful samples were from three Cambodian large commercial farms and also from Thailand. There was no indication of ASF in either of these production sources - introduction of the currently circulating strain of ASF into commercial operations would be expected to result in high mortalities (FAO, 2020; Mazur-Panasiuk, Żmudzki, \& Woźniakowski, 2019) and trigger some sort of alert, even if only in local media. There was no ASF outbreak reported in Cambodian origin provinces (Pig Progress, 2021a) during the time of our study, This raised then some concern as to the nature of the positive results. The Dse published by the ASF ELISA manufacturer's internal validation was $95.8 \%$ while the Dsp was reported up to $100 \%$ (Dixon, 2014), indicating that false-negative, but not false-positive results could occur. All the positive samples were confirmed in a retest to rule out test aberration on the days of testing, suggesting that these animals had been previously exposed to the virus. Samples that tested positive and doubtful by the antibody ELISA technique were negative when tested in the RT-PCR, indicating they were not persistently infected survivors of infection. ASF is a highly contagious disease with a mortality rate of up to $100 \%$ and a vaccine was not available. The results would indicate that under field conditions the ASF ELISA has a Dse of less than $100 \%$, unless there has been some use of vaccines that might have been imported from elsewhere. It is unlikely that an undetectable low virulence mutant (Pig Progress, 2021b) would emerge in Cambodia. Therefore, further investigations are required to determine the true nature of this ASF seropositivity.

In conclusion, an abattoir surveillance system could provide initial disease seroprevalence of high impact diseases and zoonoses for further investigation if needed. When resources are limited, the focuses of the survey should be adjusted based on the national priorities and current situations. The cost-effectiveness of a survey program could be increased through building provincial veterinary and para-veterinary capacities and cost-cutting where possible.

\section{Declarations}

\section{Acknowledgements}

This surveillance of abattoir livestock in Phnom Penh was a component of the enhancement of zoonotic disease outbreak detection in the Lao PDR and Cambodia (CAMNN3) project implemented in Cambodia by the National Animal Health and Production Research Institute (NAHPRI), General Directorate of Animal Health and Production, and the Mahidol-Oxford Tropical Medicine Research Unit (MORU). The authors are grateful for the efforts of field and laboratory staff in the NAHPRI. The authors are grateful to the Biological Threat Reduction Program (BTRP) of the Defense Threat Reduction Agency (DTRA) of the U.S. government for providing the funding.

\section{Funding}


This research was funded by the Biological Threat Reduction Program (BTRP) of the Defense Threat Reduction Agency (DTRA) of the U.S. government [contract number HDTRA1-08-D-0007]. Stuart D. Blacksell is supported by the Wellcome Trust [220211] of the United Kingdom.

For the purpose of Open Access, the author has applied a CC BY public copyright licence to any Author Accepted Manuscript version arising from this submission.

Statement of Animal Rights: An animal ethics approval for this survey was obtained from the General Directorate of Animal Health and Production (GDAHP), Cambodia (no. 5074GDAHP).

Conflicts of Interest: All authors declare that they do not have a conflict of interest.

Data availability: All data generated or analysed during this study are included in this published.

\section{Author contribution:}

Jarunee Siengsanan-Lamont

Designing, analysing the field and laboratory testing and writing up the manuscript

Sothyra Tum

Coordinating the field and laboratory testing activities, assisting in writing up the manuscript

Lida Kong

Managing the field sample collection activities in Cambodia, performing laboratory test and data analysis

Paul W. Selleck

Performing serological testing

Laurence J. Gleeson

Assisting in survey design and writing up the manuscript

Stuart D. Blacksell

Leading the study, acquiring funding and writing up the manuscript

\section{References}

1. Asia Beef Network., 2020. Cambodia Country Profile: The Processing Sector. http://www.asiabeefnetwork.com/country-profiles/cambodia/the-processing-sector/

2. Auerswald, H., Ruget, A. S., Ladreyt, H., In, S., Mao, S., Sorn, S.,.. . Cappelle, J., 2020. Serological evidence for Japanese encephalitis and West Nile virus infections in domestic birds in Cambodia. 
Frontiers in veterinary science, 7, 15.

3. Blacksell, S., Khounsy, S., Conlan, J., Gleeson, L., Colling, A., \& Westbury, H., 2008. Foot and mouth disease in the Lao People's Democratic Republic: II. Seroprevalence estimates, using structured surveillance and surveys of abattoirs. Revue scientifique et technique, 27(3), 851.

4. Cannon, R. M., \& Roe, R. T., 1982. Livestock Disease Surveys: A Field Manual for Veterinarians. Queanbeyan, (Better Printing Service, NSW).

5. Chan, S., 2020. Government massively cuts imports of live pigs. Khmer Times. https://www.khmertimeskh.com/50725748/government-massively-cuts-imports-of-live-pigs/. Accessed 22 May 2020

6. CISA-INIA, Centro de Investigación en Sanidad Animal., 2015. Validation study report of ID Screen ${ }^{\circledR}$ African Swine Fever Competition, (IDVET, Madrid).

7. Colombe, S., Watanapalachaigool, E., Ekgatat, M., Ko, A. I., \& Hinjoy, S., 2018. Cross-sectional study of brucellosis and Q fever in Thailand among livestock in two districts at the Thai-Cambodian border, Sa Kaeo province. One Health, 6, 37-40.

8. Darith, S., Xu, S., Yu, W., Abdul-Gafar, A., Kennvidy, S., Ratanak, O., \& Mbala, E. M., 2017. Potentials and Constraints of Small-Scale Livestock Productions in Cambodia. World Journal of Engineering and Technology, 5(2), 15-22.

9. DeCook, R., 2011. Logistic Regression. In Applied Linear Regression (pp. 3-28). http://homepage.stat.uiowa.edu/ rdecook/stat3200/notes/LogReg_part2_4pp.pdf. Accessed 22 May 2020

10. Desvaux, S., Sorn, S., Holl, D., Chavernac, D., Goutard, F., Thonnat, J.,.. . Roger, F., 2006. HPAl surveillance programme in Cambodia: results and perspectives. Developments in biologicals, 124, 211-224.

11. Dixon, L., 2014. ASFV challenges for diagnosis. https://www.oie.int/eng/oiecicasf_2014/docs/pdf/13_Linda_Dixon/files/assets/common/downloads/13_Linda_Dixon.pdf. Accessed 22 May 2020

12. Ear, S., 2012. Emerging infectious disease surveillance in southeast Asia: Cambodia, Indonesia, and the US naval area medical research unit 2. Asian Security, 8(2), 164-187.

13. FAO, Food and Agriculture Organisation of the United Nations., 2020. ASF situation in Asia update. http://www.fao.org/ag/againfo/programmes/en/empres/ASF/situation_update.html. Accessed 22 May 2020

14. Fox, J., 2020. ANOVA. https://www.rdocumentation.org/packages/car/versions/3.0-8/topics/Anova Accessed 22 May 2020

15. Goutard, F. L., Binot, A., Duboz, R., Rasamoelina-Andriamanivo, H., Pedrono, M., Holl, D.,.. . Figuié, M., 2015. How to reach the poor? Surveillance in low-income countries, lessons from experiences in Cambodia and Madagascar. Preventive veterinary medicine, 120(1), 12-26. 
16. Graul, C., 2016. leafletR: Interactive Web-Maps Based on the Leaflet JavaScript Library. R package version 0.4-0. http://cran.r-project.org/package=leafletR. Accessed 22 May 2020

17. Holl, S., 2018,. Avian Influenza situation in Cambodia. Paper presented at the Avian Health Workshop July 17-19, 2018, University of Japan.

18. Horm, S. V., Sorn, S., Allal, L., \& Buchy, P., 2013. Influenza A (H5N1) virus surveillance at live poultry markets, Cambodia, 2011. Emerging infectious diseases, 19(2), 305.

19. Hul, V., Delaune, D., Karlsson, E. A., Hassanin, A., Tey, P. O., Baidaliuk, A.,.. . Mazet, J., 2021. A novel SARS-CoV-2 related coronavirus in bats from Cambodia. BioRxiv.

20. ID.VET., 2014. ID Soft. https://www.id-vet.com/idsoft-software-now-available-for-use-with-idscreenpoultry-elisa-kits/. Accessed 22 May 2020

21. ID.VET., 2019. Internal validation report, ID Screen ${ }^{\circledR}$ Classical Swine Fever E2 Competition, (ID.VET, France).

22. ID.VET., 2020. Internal validation report,ID screen ${ }^{\circledR}$ PRRS indirect, (ID.VET, France).

23. Kerr, J., Sieng, S., \& Scoizec, A., 2013. Working with traders to understand livestock movements and spread of animal disease in Cambodia and Lao PDR. Cattle health, production and trade in Cambodia, 101.

24. Kunavongkrit, A., \& Heard, T., 2000. Pig reproduction in south east Asia. Animal reproduction science, 60, 527-533.

25. Mazur-Panasiuk, N., Żmudzki, J., \& Woźniakowski, G., 2019. African swine fever virus-persistence in different environmental conditions and the possibility of its indirect transmission. Journal of veterinary research, 63(3), 303-310.

26. Microsoft Corporation., 2020. Microsoft Excel. https://office.microsoft.com/excel Accessed 22 May 2020

27. Mori, M., \& Roest, H.-J., 2018. Farming, Q fever and public health: agricultural practices and beyond. Archives of Public Health, 76(1), 1-9.

28. OIE, World Organization for Animal Health., 2018. Manual of Diagnostic Tests and Vaccines for Terrestrial Animals. In Chap. 3.01.04: Brucellosis (pp. 368-370), (OIE, France).

29. OIE, World Organization for Animal Health., 2019. Manual of Diagnostic Tests and Vaccines for Terrestrial Animals. In Chap. 3.8.1. African swine fever (pp. 8-9), (OIE, France).

30. Olmo, L., Ashley, K., Young, J., Suon, S., Thomson, P., Windsor, P., \& Bush, R., 2017. Improving smallholder cattle reproductive efficiency in Cambodia to address expanding regional beef demand. Tropical animal health and production, 49(1), 163-172.

31. Osbjer, K., Berg, M., Sokerya, S., Chheng, K., San, S., Davun, H.,.. . Zohari, S., 2017. Influenza A virus in backyard pigs and poultry in rural Cambodia. Transboundary and Emerging Diseases, 64(5), 15571568.

32. Pham, L., Smith, D., Sotheun, S., \& Vitau, S., 2015. Cambodia beef cattle industry. Paper presented at the Regional Workshop on Beef Markets and Trade in Southeast Asian and China. Ben Tre, Vietnam, 
30th November-3rd December, 2015.

33. Pig Progress., 2021a. ASF outbreak in Asia. https://www.pigprogress.net/Health/African-SwineFever/ASF-China/All-outbreaks-and-transport-bans/. Accessed 22 May 2020

34. Pig Progress., 2021b. ASF China: Mutations confirmed by Chinese scientists. https://www.pigprogress.net/Health/Articles/2021/3/ASF-China-Mutations-confirmed-by-Chinesescientists-715566E/. Accessed 22 May 2020

35. Pisei, H., 2020,). Pig farmers in need of more government support to expand. The Phnom Penh Post. https://www.phnompenhpost.com/business/pig-farmers-need-more-government-support-expand. Accessed14 April 2020

36. Reiczigel, J., Földi, J., \& Ózsvári, L., 2010. Exact confidence limits for prevalence of a disease with an imperfect diagnostic test. Epidemiology \& Infection, 138(11), 1674-1678.

37. Roche, X., Rozstalnyy, A., TagoPacheco, D., Pittiglio, C., Kamata, A., Beltran Alcrudo, D.,.. . Larfaoui, F., 2021. Introduction and spread of lumpy skin disease in South, East and Southeast Asia: Qualitative risk assessment and management: Food \& Agriculture Org.

38. RStudio Team., 2015. RStudio: Integrated Development for R.: RStudio, Inc., Boston, MA. http://www.rstudio.com/. Accessed 22 May 2020

39. Shankar, B., Morzaria, S., Fiorucci, A., \& Hak, M., 2012. Animal disease and livestock-keeper livelihoods in Southern Cambodia. International Development Planning Review, 34(1), 39.

40. Siengsanan-Lamont, J., Douangngeun, B., Theppangna, W., Khounsy, S., Phommachanh, P., Selleck, P. W.... . Blacksell, S. D., 2021. The development of an abattoir-based surveillance system in Lao PDR for the detection of zoonoses in large ruminants: $Q$ fever and brucellosis seroepidemiology as a pilot study. Animals, 11(3), 742.

41. Soetewey, A., 2020. Fisher's exact test in R: independence test for a small sample. https://towardsdatascience.com/fishers-exact-test-in-r-independence-test-for-a-small-sample$56965 \mathrm{db} 48 \mathrm{e} 87$. Accessed 28 Jan 2020

42. Sothoeun, S., Young, J., \& Windsor, P., 2013. Livestock infectious disease status in Cambodia. Cattle health, production and trade in Cambodia, 44.

43. Souriya, V., Piamsomboon, P., Ajariyakhajorn, K., Damrongwatanapokin, T., \& Inchaisri, C., 2019. Risk factors of foot and mouth disease in an endemic area on low vaccination rate in Xayaboury province of Lao People's Democratic Republic (Lao PDR). Tropical animal health and production, 1-12.

44. Sripiachai, P., 2021. Lumpy skin disease outbreak in cattle in Nakhon Phanom. https://www.bangkokpost.com/thailand/general/2120295/lumpy-skin-disease-outbreak-in-cattle-innakhon-phanom. Accessed 22 May 2020

45. Stevenson, M., 2020. epiR: Tools for the Analysis of Epidemiological Data. R package version 1.014. https://CRAN.R-project.org/package=epiR. Accessed 22 May 2020

46. Thammakarn, C., Hung, P. H. S., \& Eardmusic, S., 2018. Co-infection of PRRSV, PCV2 and Pasteurella multocida in a pig farm at Rachaburi province of Thailand. Proceeding of AIC: Health and Life Sciences, 8(1). 
47. Tornimbene, B., Chhim, V., Sorn, S., Drew, T., \& Guitian, J., 2014. Knowledge, attitudes and practices of Cambodian swine producers in relation to porcine reproductive and respiratory syndrome (PRRS). Preventive veterinary medicine, 116(3), 252-267.

48. Tornimbene, B., Frossard, J.-P., Chhim, V., Sorn, S., Guitian, J., \& Drew, T., 2015. Emergence of highly pathogenic porcine reproductive and respiratory syndrome (HP-PRRS) in medium-scale swine farms in southeastern Cambodia. Preventive veterinary medicine, 118(1), 93-103.

49. Tum, S., Robertson, I. D., Edwards, J., Abila, R., \& Morzaria, S., 2015. Seroprevalence of foot-andmouth disease in the southern provinces of Cambodia. Tropical animal health and production, $47(3)$, 541-547.

50. Vergne, T., Goutard, F., Holl, D., Bellet, C., Roger, F., Grosbois, V., \& Dufour, B., 2011. Capture-recapture as a tool to assess animal disease surveillance: the example of foot-and-mouth disease in Cambodia. Epidémiologie et santé animale.

51. Woonwong, Y., Do Tien, D., \& Thanawongnuwech, R., 2020. The future of the pig industry after the introduction of African swine fever into Asia. Animal Frontiers, 10(4), 30-37.

52. Xuxin., 2019. Cambodia imports 1,500 pigs from Thailand per day amid ban of import from Vietnam. Xinhua. http://www.xinhuanet.com/english/2019-05/21/c_138077390.htm. Accessed 22 May 2020

53. Young, J., Rast, L., Suon, S., Bush, R., Henry, L., \& Windsor, P., 2014. The impact of best practice health and husbandry interventions on smallholder cattle productivity in southern Cambodia. Animal Production Science, 54(5), 629-637.

54. Zhang, A., Young, J., Suon, S., Ashley, K., Windsor, P., \& Bush, R., 2017. Investigating the financial impact of porcine reproductive and respiratory syndrome on smallholder pig farmers in Cambodia. Tropical animal health and production, 49(4), 791-806.

\section{Figures}

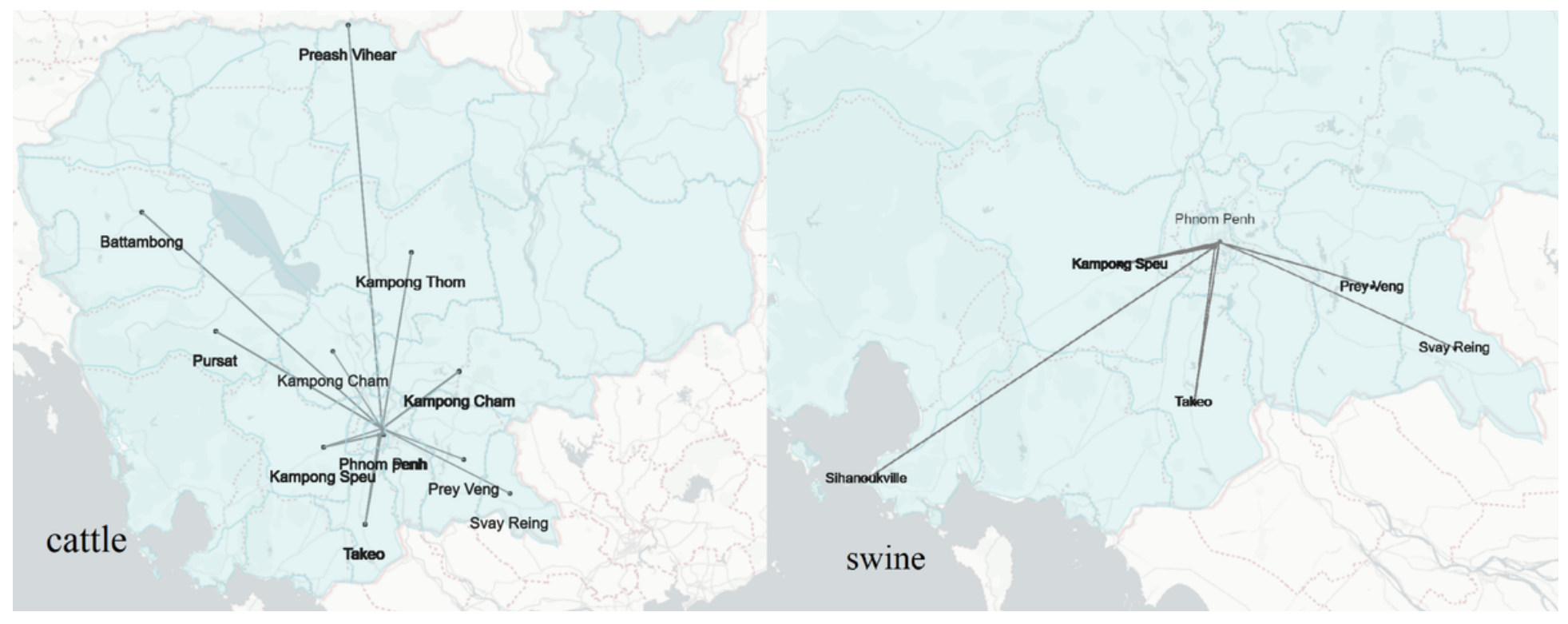

Figure 1 
Movements of Cambodian cattle (left) and pigs (right) from province of origin to slaughterhouses in Phnom Penh (black dots and province names represent animal origins) 